\title{
A participação nas decisões por meio da representação por delegados nas as- sembleias gerais do SICOOB COOPEMATER/PA
}

\author{
The participation in th decisions of representation by delegates at general assemblies \\ of SICOOB COOMPEMATER/PA
}

\begin{abstract}
Resumo
O presente artigo propõe-se a analisar a percepção dos associados na participação das decisões nas assembleias gerais, representados por seus delegados na Cooperativa SICOOB COOPEMATER. Na metodologia, utilizou-se o estudo de caso exploratório, as pesquisas Survey e a quantitativa e, como instrumento de coleta de dados, o questionário estruturado, enviado pela Internet aos associados da cooperativa. $O$ resultado demonstrou que os cooperados estão satisfeitos, sentindo-se participantes das decisões da cooperativa através da representação por delegados, entretanto essa participação ainda é muito baixa. Considerando o princípio da gestão democrática pelos associados nos processos de gestão das cooperativas, conclui-se que a educação cooperativista é uma estratégia que pode trazer consequências positivas na compreensão dos associados sobre a importância de sua participação em seus diferentes níveis organizacionais e na gestão democrática da cooperativa.
\end{abstract}

Palavras-chave: Participação. Assembleias. Gestão Democrática. Associados.

\begin{abstract}
This article purpose analyzes the perceptions of member in participation decision at general meetings represented by their delegates in the cooperative SICOOB COOPEMATER. In the methodology we used the exploratory case study, the Survey research, quantitative research and how data collected through the structured questionnaire sent over the Internet to members of the cooperative. The result showed that the cooperative members are satisfied and the sense of participation in cooperative's decisions through the representation of delegates but participation is still very low. Considering the principle of democratic management by the members in the cooperative management processes, it is concluded that cooperative education is a strategy that can bring positive consequences in understanding the associates about the importance of their participation at different organizational levels and democratic management cooperative.
\end{abstract}

Key-words: Participation. Assemblies. Democratic Management. Associated.

Recebido: 01/09/2015 Aceito: 15/02/2016

Roberto Tadeu Ramos Morais ${ }^{1}$ e Lázaro José da Silva ${ }^{2}$

${ }^{1}$ Faculdades Integradas de Taquara, Doutorado em Desenvolvimento Regional- gislainefaccat@gmail.com - Av. Oscar Martins Rangel, 4500, Bairro Fogão Gaúcho, Centro-Taquara/RS,CEP: 95600-000

${ }^{2}$ Faculdade de Tecnologia do Cooperativismo, Especialista em Gestão de Cooperativas- 


\section{Introdução}

$\mathrm{C}$ cooperativismo tem se tornado cada vez mais objeto de análise de muitos pesquisadores, por exemplo, Kreimmeier (2010) e Filho, Marucci e Oliveira (2008), devido, principalmente, às suas características peculiares.

Kreimmeier (2010) estudou o crescimento da participação de associados jovens no quadro social da Cooperativa Languiru. Os resultados da pesquisa mostraram que o jovem produtor associa-se à cooperativa pela sua credibilidade, pela transparência na administração, para poder tomar parte nas decisões da empresa, entre outros motivos. O estudo apresentado por Filho, Marucci e Oliveira (2009) analisou os fatores de representatividade e participação como elementos necessários às boas práticas de governança em cooperativas de crédito. Os resultados indicaram existir um amplo espaço para desenvolvimento da participação nas cooperativas de crédito brasileiras.

A forma de organização e funcionamento de uma cooperativa difere muito da de uma empresa comum. Segundo Manica e Schmidt (2012, p. 7), a finalidade do cooperativismo "[...] visa a satisfação do interesse social, econômico individual ou coletivo do associado para proporcionar a distribuição de benefícios obtidos pela atividade cooperativista, de forma igualitária e proporcional à participação dos associados". Portanto, o cooperativismo é uma forma de organização que tem como objetivo final o desenvolvimento, não somente econômico, mas também social dos associados, de suas famílias e da comunidade como um todo. Nesse sentido, há um conjunto de princípios cooperativistas, os quais são universais, que servem como uma espécie de guia para o funcionamento das cooperativas no mundo. Um desses princípios é denominado de 'gestão democrática pelos cooperados', ou seja, as cooperativas são organizações democráticas, controladas por seus associados, os quais participam ativamente na formulação de suas políticas e na tomada de decisões.

O ramo crédito no Brasil tem crescido exponencialmente. Meinen e Port (2012) expõem que, de 1995 a 2011, os ativos das cooperativas cresceram 9.728\% enquanto o Sistema Financeiro Nacional (SFN) cresceu $758 \%$. Manter-se em crescimento constante, acima da média do mercado, exige que as cooperativas de crédito estejam em permanente contato com seus associados.
O Estado do Pará possui 566 cooperativas registradas no Sistema OCB/SESCOOP-PA (Organização das Cooperativas do Brasil/Serviço de Aprendizagem do Cooperativismo do Estado do Pará), com um total de aproximadamente 125 mil associados, sendo que o ramo crédito representa $7,6 \%$ desse total, tendo em seu quadro social aproximadamente 25 mil associados ou $20 \%$ de todos os cooperados no Estado do Pará. Em face da importância da gestão participativa no contexto do cooperativismo, o presente artigo buscará analisar a percepção dos cooperados na participação das decisões por meio da representação por delegados nas assembleias gerais. Para alcançar esse objetivo geral, foram apontadas as seguintes questões norteadoras: a) Quais são as principais dificuldades para a participação dos associados nos processos de decisão? b) Que assuntos motivam a participação dos associados nas assembleias? e c) Que estratégias são desenvolvidas para se obter a participação dos associados nos processos de gestão da cooperativa?

O presente trabalho justifica-se pela necessidade de se compreender as causas da falta de participação dos associados nos espaços de tomadas de decisões da cooperativa, considerando-se que a gestão democrática é um princípio básico para a organização e para o funcionamento do ramo crédito. A partir dessas respostas, é que será possível desenvolver estratégias para que o associado compreenda seu papel de protagonista na gestão da cooperativa.

A estrutura do texto está constituída de sete seções a partir desta Introdução. Na primeira seção, um breve histórico do surgimento do cooperativismo no Brasil e alguns esclarecimentos sobre o ramo crédito. A gestão democrática em cooperativas será abordada na segunda seção, buscando demonstrar como se distinguem das empresas tradicionais. Partindo-se de que o órgão supremo da sociedade cooperativa é a assembleia geral, a terceira seção discute as formas de condução dessas assembleias, levando-se em consideração os limites legais e estatutários. Na sequência, será abordada a participação e a representatividade dos sócios nas assembleias gerais. A metodologia da pesquisa, bem como os métodos e procedimentos utilizados, está presente na quinta seção. Os resultados e sua discussão são apresentados na sexta seção, e, por fim, a conclusão. 


\section{Referencial Teórico}

\subsection{O cooperativismo no brasil}

No Brasil, as mudanças sociais, ocorridas ao final do século XIX, como a abolição da escravatura e a proclamação da república, criaram um clima propício para a discussão do cooperativismo (HOLANDA, 2003). A primeira cooperativa que se tem registro no Brasil surgiu em Ouro Preto, Minas Gerais, no ramo consumo. A partir deste evento, proliferaram as cooperativas de consumo nos Estados de São Paulo, Rio Grande do Sul e Rio de Janeiro. Em 1902, surgiu, em Nova Petrópolis, Rio Grande do Sul, por inspiração de um padre jesuíta suíço, Theodor Amstad, a primeira cooperativa de crédito de que se tem notícia no país e que continua em atividade nos dias de hoje com a denominação de Cooperativa de Crédito de Livre Admissão de Associados Pioneira da Serra Gaúcha Pioneira/RS (PINHEIRO, 2008).

Contudo, foi na era do presidente Getúlio Vargas que se criou uma legislação própria para este tipo de organização. Nessa época de reorganização do Estado, com o discurso de que a centralização e o autoritarismo eram elementos necessários para a construção de um novo modelo econômico e político, é que teve início a implementação de diversas políticas e projetos de modernização, entre as quais o incentivo ao cooperativismo (MARQUES, 2010). O Decreto $\mathrm{n}^{\mathrm{a}}$ 22.239, de 19 de dezembro de 1932, trouxe, no seu artigo $30^{\circ}$, especificações para as cooperativas de crédito. Diz o artigo:

\footnotetext{
As cooperativas de crédito têm por objetivo principal proporcionar a seus associados créditos e moeda, por meio da mutualidade e da economia, mediante uma taxa módica de juros, auxiliando de modo particular o pequeno trabalho em qualquer ordem de atividade na qual ele se manifeste, seja agrícola, industrial, comercial ou profissional, e acessoriamente, podendo fazer com pessoas estranhas à sociedade, operações de crédito passivo e outros serviços conexos ou auxiliares de crédito.
}

Denota-se que o artigo $30^{\circ}$ reconhece as características das sociedades cooperativas de crédito e se constitui em um marco jurídico de referência para a consolidação destas. O mesmo decreto, em seu artigo $6^{\circ}, \S 8^{\circ}$, dispõe que "É licito dispor nos estatutos que só poderão ser admitidos como associados pessoas de determinada profissão, classe ou corporação". Para Pinheiro (2008), isso dá amparo às cooperativas de crédito mútuo, que passam a exigir um vínculo entre os associados. A revogação do Decreto $n^{\circ} 22.239 / 32$ ocorreu em 21 de novembro de 1966, pelo Decreto-Lei 59, regulamentado pelo Decreto $\mathrm{n}^{\circ}$ 60.597, de 19 de abril de 1967, já que a Lei $\mathrm{n}^{\circ}$ 4.595, de 31 de dezembro de 1964, havia transferido ao Banco Central do Brasil as atribuições incumbidas por lei ao Ministério da Agricultura, no que concerne à autorização de funcionamento e fiscalização de cooperativas de crédito de qualquer tipo, as quais se equiparam às instituições financeiras.

Em 1971, é promulgada a Lei $\mathrm{n}^{\circ} 5.764$, de 16 de dezembro, conhecida como a lei do cooperativismo, que define a Política Nacional de Cooperativismo e institui o regime jurídico das sociedades cooperativas. Em seu artigo $4^{\circ}$, fica estabelecido que as cooperativas distinguem-se das demais sociedades pelas seguintes características: a) adesão voluntária; b) singularidade de voto; c) quórum para deliberação da Assembleia Geral, baseado no número de associados e não no capital; d) área de admissão de associados, limitada às possibilidades de reunião, controle, operações e prestação de serviços, e e) outras. Com essas características, as cooperativas se convertem em ambientes para prática dos princípios da gestão democrática, requerendo, em sua governança, a criação de mecanismos que fortaleçam a participação dos associados e a sua representatividade nas principais decisões da cooperativa (VENTURA, FILHO e SOARES, 2009).

\subsection{Gestão democrática em cooperativas}

A participação democrática dos sócios é a característica mais conhecida do modelo de gestão cooperativista e o que a distingue das empresas mercantis ou tradicionais (PINHEIRO, 2008). A origem etimológica da palavra participação está em particípio, do latim, que significa ter parte na ação. Bordenave (1994, p. 22), por sua vez, ressalta que participação vem da palavra parte. "Participação é fazer parte, tomar parte e ter parte [...]". Para o autor, essas três expressões se referem a formas distintas de participação, com implicações diferentes para as partes envolvidas. Isso indica que é possível fazer parte sem tomar parte, sendo que a segunda expressão é aquela que se aproxima mais intensamente daquilo que o cooperativismo denomina de participação. Daí se deriva à diferenciação 
entre participação ativa (tomar parte) e passiva (fazer parte). Existe ainda um outro tipo de participação, denominada de voluntária, em que o grupo é criado pelos próprios participantes, os quais definem sua forma de organização, seus objetivos e métodos.

Bordenave (1994) cita, enquanto exemplo, os sindicatos livres, as associações de moradores, as cooperativas e os partidos políticos. Acrescenta ainda o autor que, ao se avaliar a participação num grupo ou organização, duas perguntas são fundamentais: 1) Qual é o grau de controle dos membros sobre as decisões? e 2) Quão importantes são as decisões de que se pode participar? Como resposta a essas duas perguntas, Bordenave (1994) apresenta uma escala que vai da participação à informação: os membros de um grupo são apenas informados sobre algo, passando pela consulta, a recomendação, a cogestão, a delegação, chegando até ao estágio máximo de participação, denominada de autogestão. A autogestão é uma forma de administração participativa em que os indivíduos têm que trabalhar de forma coletiva em todas as etapas do processo, em regime de democracia direta. $\mathrm{O}$ indivíduo é dono de seu empreendimento e, por isso, cabe-lhe tomar as decisões em conjunto com os demais integrantes da organização, e sua participação é fundamental, no sentido de que o processo participativo impulsiona a criatividade dos membros, aumenta a produtividade, cria uma identidade de grupo, corrige falhas gerenciais e direciona novos rumos para o negócio (SINGER, 2002).

Segundo Mattos (2013), dois aspectos importantes devem caminhar concomitantemente na autogestão de uma cooperativa: a) a gestão transparente e democrática e, b) a participação ativa dos associados nas decisões. O simples fato de o cooperado entregar sua produção para a cooperativa não constitui cooperação; ela só se constitui quando o sócio exerce suas obrigações de dono da cooperativa, também se envolvendo nas decisões de sua cooperativa. Há necessidade de gestores comprometidos e preparados para o gerenciamento da cooperativa, mas não lhes cabe somente a tomada de decisão, pois a cooperativa deve ser gerida democraticamente pelos associados, ou seja, quem deve decidir o futuro do negócio é o cooperado, desde que municiado de informações precisas e fundamentadas, fornecidas pelos gestores para que a assembleia geral, órgão máximo de uma cooperativa, possa decidir que rumos tomar no curto, médio e longo prazos.

A eficiência de uma sociedade cooperativa está amparada, principalmente, por seu capital humano. Daí a necessidade de repensar a forma de participação e de conscientização dos cooperados, a fim de alcançar a sustentabilidade de um empreendimento que precisa conciliar o capital humano e o financeiro. Duarte e Vieira (2010) já alertavam de que é necessário estimular a participação e apoiar projetos que possam contribuir para o desenvolvimento do capital humano, porém a participação não ocorre somente por meio de assembleia geral; é extremamente importante que o associado tenha uma atuação mais ativa junto à cooperativa. Para isso, é necessário que as cooperativas criem outros canais de participação junto a seus cooperados, estimulandoos à participação e à compreensão nas assembleias (DUARTE e VIEIRA, 2010).

Os referidos autores apontam a videoconferência como uma ferramenta de comunicação que contribui para diminuir a distância geográfica daqueles que, normalmente, não teriam condições de participar das assembleias. Esse sistema tecnológico é uma metodologia que permite que se trabalhe de forma cooperativa, compartilhando informações e materiais de trabalho sem a necessidade de locomoção. Em vista do custo-benefício, o recurso é seguro, confiável, confortável e cômodo, podendo se tornar mais barato do que se realizar uma assembleia de delegados presencialmente.

Porém, não basta a simples disseminação de informações. É preciso ousar e planejar a conscientização para o modelo de representação por delegados. Essa conscientização poderá ser alcançada com a educação cooperativista, dirigida para o tema em questão. Este desafio é permanente, pois cada região, local ou comunidade possui sua cultura, e é necessário preservá-la. O quinto princípio do cooperativismo enaltece a educação cooperativista ao afirmar que "As cooperativas promovem a educação e a formação de seus membros, dos representantes eleitos e dos trabalhadores, de forma que estes possam contribuir eficazmente para o desenvolvimento de suas cooperativas" (Aliança Cooperativa Internacional, 1995).

Portanto, a educação cooperativista passa a ser entendida como uma ação cooperativa, de descoberta do conhecimento e decorrente de uma socializa- 
ção, uma construção de todos os seus membros (BASSO, DUARTE e FLORES, 2012).

\subsection{Representação por delegados nas assemblei- as gerais em cooperativas}

A assembleia geral dos associados é o órgão supremo da sociedade cooperativa, conforme limites legais e estatutários, com competência para decidir os negócios relativos ao objeto da cooperativa e zelar pelo seu desenvolvimento e defesa. As deliberações definidas neste órgão vinculam todos, ainda que ausentes ou discordantes; portanto se faz necessária a efetiva participação dos cooperados. Porém, a participação é pouco expressiva. Estudo realizado em 2007, pelo Banco Central do Brasil, apontava que menos de $10 \%$ dos associados haviam participado da última Assembleia Geral Ordinária (AGO) nas cooperativas de crédito brasileiras (VENTURA, FILHO e SOARES, 2009).

De acordo com os autores, as cooperativas que optam pelo regime de representação por delegado possuem maior representatividade dos associados. Esse modelo de representação está previsto no artigo 42 da lei máxima do cooperativismo e permite que as cooperativas singulares com mais de 3.000 associados, ou cujos cooperados residam a mais de $50 \mathrm{Km}$ da sede (âmbito regional, estadual ou nacional), e que tenham baixa representatividade ou pouca participação efetiva dos associados nas assembleias, utilizem-se deste mecanismo para dirimir as dificuldades de representatividade de grupos e de participação. Quando for adotada a representação por delegados, o estatuto social deve disciplinar aspectos como: a) a quantidade de grupos seccionais em que se divide a área de atuação da cooperativa, distribuídos proporcionalmente ao número de associados; b) o número de delegados, a época e a forma de sua escolha e o prazo de seu mandato (LEI 5.764/1971, art. $42, \S 3^{\circ}$, com a redação dada pela Lei 6.981/1982).

A singularidade do voto nas assembleias gerais de delegados (cada delegado disporá de um voto) e o quorum mínimo para sua instalação também devem ser contemplados no estatuto, bem como cláusula estabelecendo a extinção desse instituto, quando for constatada a impossibilidade de reunião por falta de quorum, caso em que poderá ser necessária a redução da área de atuação da cooperativa.

Os delegados devem ser associados da res- pectiva cooperativa e estar no gozo de seus direitos, porém não podem exercer cargo eletivo na sociedade. O modelo de representação por delegados facilita a coordenação do processo assemblear e melhora a interlocução entre gestores e associados, reduzindo o custo envolvido.

\subsection{Participação e representatividade de sócios nas assembleias gerais}

A participação dos associados ou representantes de grupos legítimos nas assembleias pode ser avaliada tanto quantitativa, ou seja, pelo número de presenças, quanto qualitativamente, pela sua contribuição ao debate, às deliberações e à tomada de decisão (VENTURA, FILHO e SOARES, 2009).

Os autores também afirmam que, ao participarem do processo de convocação, realização e deliberação das assembleias, conferem maior legitimidade ao controle interno, desencadeado pelos mecanismos de governança corporativa. Embora as cooperativas estejam sob o controle e propriedade de seus associados, na prática, à medida que esse número de cooperados cresce, os integrantes tendem a ceder o controle a um conselho eleito e a gestão a um grupo de executivos (BIRCHALL e SIMMONS, 2004).

Por se configurarem sociedades de pessoas, as cooperativas devem dispor de mecanismos internos de participação e confiança mútua entre os associados. A participação dos associados na cooperativa é condição fundamental para o cumprimento de sua missão, pois contribui para uma gestão democrática, melhora a fiscalização e aumenta a solidez do negócio, alinhando os interesses internos às expectativas dos cooperados. A participação dos associados na cooperativa deve ser estimulada com instrumentos que lhes possibilitem serem ouvidos e se expressarem. Entre os instrumentos disponíveis, encontramse as reuniões periódicas e as pré-assembleias, que permitem esclarecer aos associados as atividades e os resultados da cooperativa. Dessa forma, está se contribuindo para a formação de ambientes adequados à coleta de suas críticas e propostas, além de fornecer o sentimento de pertencimento (VENTURA, FILHO e SOARES, 2009).

Filho, Marucci e Oliveira (2008) apresentam os resultados obtidos em pesquisa realizada pelo Banco Central do Brasil quanto aos aspectos da partici- 
pação e mecanismos de representação nas cooperativas de crédito brasileiras. Segundo a pesquisa, a participação dos associados em assembleias é baixa. Os resultados demonstraram que a maioria das cooperativas possui frequência menor de $10 \%$ na assembleia geral. A pesquisa destaca, ainda, que a maior participação relativa se dá nas cooperativas que optam pelo regime de representação por delegados. Entretanto, no ramo crédito, somente 9,17\% das cooperativas afirmaram que a participação na assembleia ocorre no modelo de representação por delegados.

Ventura, Filho e Soares (2009) realizaram uma pesquisa na qual avaliaram os possíveis motivos para a baixa participação dos associados em assembleias gerais. Os resultados apontaram para: a) falta de confiança do cooperado na administração da cooperativa; b) falta de conhecimento do cooperado a respeito de importância em participar na assembleia; c) dificuldade no deslocamento da residência do cooperado para o local da assembleia; d) falta de realização de festividades e sorteios; e) falta de mobilização ou de convite ao associado, entre outros. A reversão desse quadro é fundamental, pois é direito e obrigação fundamental do cooperado definir os objetivos de sua cooperativa. Atuar de forma passiva nas questões de sua organização foge ao espírito cooperativista e pode representar riscos para a mesma (PINHEIRO, 2008). Como forma de estimular a participação e gerar sentimento de pertencimento dos associados perante a cooperativa, as assembleias regionais ou pré-assembleias são instrumentos fundamentais e funcionais, já que facilitam e amadurecem o debate muitas vezes inviável no momento da assembleia geral, seja por falta de tempo, extensão da pauta, timidez do cooperado, centralização do debate, entre outros motivos (MARQUES, 2010).

\section{Metodologia}

\subsection{SICOOB COOPEMATER/PA}

Fundada em 07 de junho de 1989, a partir de um grupo de 36 funcionários da EMATER/PA (Empresa de Assistência Técnica e Extensão Rural) de ajuda mútua de empréstimos, a Coopemater/SA conta em seu quadro social com mais de 800 sócios, distribuídos em todo o Estado do Pará, sendo a única cooperativa neste Estado a utilizar o sistema de de- legados para as deliberações nas assembleias gerais. De 1989 até 12 de março de 2000, a cooperativa funcionou nas dependências da EMATER/PA, em sala cedida pela empresa. Nesta data, inaugurou a sua sede própria, localizada na Avenida Almirante Barroso, 4790, na capital do Estado, onde funciona até hoje.

Com a Resolução n ${ }^{\circ} 2.608$, de 27 de maio de 1999, dando possibilidade de associação aos servidores de órgãos afins, o Conselho de Administração da COOPEMATER sugeriu a alteração do estatuto social da cooperativa para garantir aos empregados e servidores de outros órgãos a associação. A aprovação ocorreu na $17^{\mathrm{a}}$ Assembleia Geral Extraordinária (AGE), no ano de 2000. Mais tarde, com a criação da Secretaria Especial de Produção do Estado do Pará, fez-se uma nova alteração do estatuto social, expandindo a área de ação da cooperativa para todo o Estado do Pará, mudando sua denominação para Cooperativa de Economia e Crédito Mútuo dos Empregados e Servidores dos Órgãos do Setor Público Produtivo do Estado do Pará Ltda., bem como a inclusão de outros órgãos, que vieram a fazer parte do estatuto da COOPEMATER, aprovado na $21^{\mathrm{a}} \mathrm{AGE}$, em março de 2003.

Em março de 2004, foi aprovada a instituição de assembleia geral por delegados em substituição as de associados, alteração essa imposta pelo Banco Central, que determinava essa modificação ou a limitação da área de atuação à região metropolitana de Belém/PA.

Essa imposição foi justificada pelo fato de o Estado do Pará possuir 144 municípios e uma extensão territorial de 1.247.954,66 $\mathrm{Km}^{2}$, além de ser intercortado por diversos rios e afluentes, com uma bacia hidrográfica que abrange uma área de 1.253.164 $\mathrm{Km}^{2}$, o que torna demorado e difícil o deslocamento de algumas regiões do Estado para a capital, Belém, que fica situada no extremo norte do Estado, o que limitaria a participação de todos os associados nas assembleias gerais, que ocorrem na sede da cooperativa, situada na capital do Estado. Já em junho de 2012, foi aprovada, em assembleia geral conjunta da COOPEMATER e da COOPERSAGRI (Cooperativa de Economia e Crédito Mútuo e Serviços da Secretaria de Agricultura do Pará Ltda.), a união num processo de incorporação.

A COOPEMATER, por estar inserida no Sistema Cooperativo de Crédito do Brasil -SICOOB BRASIL, padronizou seus normativos e alterou sua 
denominação no estatuto social, em abril de 2013, passando a adotar a nova sigla SICOOB COOPEMATER. Portanto, a cooperativa em estudo foi escolhida pela sua experiência, desde 2004, na participação de delegados em assembleia geral, associando-se o fato de que se busca analisar se o processo permite efetivamente que os associados se expressem e sejam ouvidos, promovendo a representatividade e o debate democrático.

\subsection{Métodos e procedimentos}

A pesquisa exploratória foi realizada uma vez que há pouco conhecimento acumulado e sistematizado a respeito da percepção dos associados na participação das decisões nas assembleias gerais representados por delegados. Utilizou-se a pesquisa Survey, acompanhada de um estudo de caso. O levantamento (Survey) analisou quantitativamente as percepções dos associados do SICOOB COOPEMATER de forma direta. O universo desta pesquisa foi constituído da totalidade dos cooperados regularmente cadastrados na cooperativa como sócios até junho de 2013, cujos e-mails estavam devidamente registrados em suas fichas associativas. Assim, a amostra da presente pesquisa representou aproximadamente $27 \%$, do total de 788 associados, ou seja, 215 cooperados. Destes, 175 efetivamente responderam às perguntas, integrando 9 das $16 \mathrm{sec}-$ cionais. Trata-se, pois, de uma amostra nãoprobabilística intencional por acessibilidade. Cumpre lembrar que todos os respondentes autorizaram e permitiram a realização da pesquisa, respondendo ao questionário.

O questionário utilizou a metodologia da escala de Likert, que é o conceito de avaliação de percepção mais indicado nas pesquisas de opinião, pois permite medir com maior precisão a forma como as pessoas percebem algo (BRANDALISE, 2005). A escala de Likert, utilizada neste estudo, continha cinco opções de resposta unipolar, conforme Tabela 1 .

Tabela 1 - Escala de Likert

\begin{tabular}{c|c}
\hline Escala de Likert & Opções de Respostas \\
\hline 5 & Concordo plenamente \\
4 & Concordo \\
3 & Concordo parcialmente \\
2 & Discordo \\
\hline 1 & Discordo plenamente \\
\hline
\end{tabular}

Fonte: O autor (2015)

A escolha pela escala de cinco pontos deve-se ao fato de que os respondentes têm dificuldade em definir seu ponto de vista em uma escala com mais de cinco opções de resposta. Significa que, se forem fornecidas mais de cinco opções de resposta, as pessoas tendem a escolhê-las aleatoriamente, prejudicando a importância dos dados. O questionário foi composto, inicialmente, pela qualificação do associado, onde se identifica o sexo, a escolaridade e a seccional a que pertence. Completam o questionário dezoito afirmativas. Foi elaborado um pré-teste, encaminhado por e-mail a sete cooperados selecionados especificamente para analisarem as prováveis dúvidas quanto às questões elaboradas. Após o préteste, o questionário foi enviado, no mês de fevereiro de 2014, via e-mail, aos associados. Do total de 215 e-mails enviados, observou-se, através do Mail
Delivery Subsystem, que quarenta e-mails não foram entregues por inconsistência do endereço eletrônico ou algum motivo que os pesquisadores desconhecem. O questionário não possuía identificação por nome, preservando, assim, os respondentes.

A análise dos dados coletados foi realizada por meio de análise estatística (médias gerais, médias por grupo de variável e percentagem), considerando o escore de resultados da análise de médias da seguinte forma:

- Escore de 1 (um) a 2,9 (dois vírgula nove) com necessidade de melhoria;

- Escore de 3,0 (três) a 3,9 (três vírgula nove) como satisfatória; e,

- Escore acima de 4,0 (quatro) como excelente. 
Esta forma de análise classifica e analisa os resultados obtidos, traduzindo-os em números, opiniões e informações.

\subsection{Perfil dos participantes}

Observou-se que $24 \%$ dos cooperados que responderam ao questionário são do gênero feminino, e $76 \%$ do masculino, com $60 \%$ acima da faixa etária dos 35 anos de idade. Do total dos respondentes, $80 \%$ têm o ensino superior, em nível de graduação, e $20 \%$ possuem especialização (Lato Sensu). As seccionais com maior percentagem de respondentes foram, nesta ordem, Emater Ilhas (45\%), Emater Central (18\%) e Emater Marabá (12\%), totalizando $75 \%$ entre as seccionais. As outras quinze seccionais representaram $25 \%$ dos respondentes.

\section{Análise dos dados}

A respeito da primeira afirmativa da pesquisa, relacionada à percepção dos cooperados de se sentirem participantes nas decisões das assembleias gerais, representados por seus delegados, observou-se que a média alcançada $(3,3)$, baseada na escala de Likert de cinco pontos de concordância crescente ainda é baixa. Buscando dar contraponto a essa posição, na quinta afirmativa, buscou-se saber se a representação por delegados não diminui o poder de decisão do cooperado nas diretrizes da cooperativa, e o resultado médio foi $(3,0)$. Os associados apresentam esse sentimento por entenderem que não participam do processo de tomada de decisão da cooperativa. Para assegurar a qualidade da representação, é fundamental a interlocução entre representantes e representados. Embora os resultados não estejam em uma escala de excelência, já é possível perceber que os apontamentos realizados vão ao encontro do que é discutido por Ventura, Filho e Soares (2009).

Quando afirmam que as pré-assembleias não são realizadas $(3,4)$, presume-se que esses não discutem os assuntos abordados; dessa forma, não há participação, pois os delegados não levam as decisões aprovadas pelo grupo da seccional. Consequentemente, os associados não terão nenhuma influência nas decisões deliberadas nas assembleias gerais. Observa-se, aqui, a participação passiva enunciada por Pinheiro (2008).
A segunda afirmativa procurava verificar a percepção dos cooperados sobre o sistema de representação por delegados do SICOOB COPEMATER. Para os associados, é a melhor opção para se ter representatividade de todas as microrregiões do Estado do Pará, devido a sua grande extensão territorial. Ao alcançar a média de $(3,6)$, fica demonstrada a concordância da maioria de que esse sistema é o que permite maior representatividade dos associados, uma vez que, se as assembleias gerais fossem realizadas na capital, extremo norte do Estado, dificilmente teriam associados de todas as regiões. $\mathrm{O}$ artigo 42 da Lei $\mathrm{n}^{\circ} 5.764 / 71$ se faz presente ao admitir a delegação para aquelas cooperativas que possuam mais de 3.000 filiados, ou que estejam residindo a mais de $50 \mathrm{~km}$ da sede.

O grau de concordância de $(3,4)$ confirmou que, para os associados, a melhor forma de deliberação das decisões nas assembleias gerais do SICOOB COPEMATER é o sistema delegado, devido a sua extensa área de atuação, ratificando, portanto, a segunda afirmativa. Se por um lado a participação é importante na vida da cooperativa, por outro, um volume muito grande de participantes nas assembleias gerais pode dificultar a sua organização e a sua própria condução. Os resultados apontam que a representação por delegados qualifica a participação dos associados, dá sustentação ao negócio e possibilita a racionalização da gestão.

A quarta afirmativa - Existe interlocução entre delegados e associados representados - e a sexta assertiva - Os delegados, nas deliberações de decisões nas assembleias gerais SICOOB COPEMATER, votam de acordo com o desejo dos associados representados apresentaram média de $(2,8)$, ratificando a décima oitava afirmativa. Isso denota que há necessidade de aproximação dos delegados com os associados. Esta quase ausência de interlocução dificulta a condução do processo assemblear, aumentando os custos envolvidos, bem como dificulta o diálogo e a percepção das necessidades dos associados. Assim, mais uma vez, fica claro que o debate em assembleias regionais ou pré-assembleias é que amadurece o debate (MARQUES, 2010). As pré-assembleias nas seccionais são fundamentais para legitimar a participação de todos os associados, sétima afirmativa, a qual obteve média $(4,1)$, assinalando a importância para os associados da realização das pré-assembleias de forma a legitimar sua participação nas decisões. As pré-assembleias, ante- 
riores às assembleias gerais, de acordo com os respondentes, fortalecem a participação e o ativismo dos associados, a fim de discutir os assuntos constantes na pauta da assembleia.
A partir da oitava até a décima segunda afirmativa, foram analisados os motivos da não participação dos associados nas pré-assembleias. A Tabela 2 apresenta os motivos e as médias.

Tabela 2 - Motivos de não participação em assembleias gerais

\begin{tabular}{c|c}
\hline Motivos & Média \\
\hline Dificuldade de deslocamento & 3,4 \\
Tempo gasto & 2,8 \\
Não faz diferença ir & 2,8 \\
Confiança na Administração & 2,8 \\
Falta de divulgação & 3,1 \\
\hline Média Geral & 2,98 \\
\hline
\end{tabular}

Fonte: Dados da Pesquisa (2014)

Fica evidente que os maiores motivos estão na dificuldade de deslocamento em um Estado com extensão territorial tão vasta e que a cooperativa falha na divulgação das pré-assembleias, não alcançando a mobilização necessária para o sucesso do evento. Por outro lado, a pesquisa deixa claro que o associado deseja participar e não se preocupa com o tempo disponibilizado para esse envolvimento. Evidencia, também, que o cooperado tem consciência de que é importante sua participação nas deliberações das diretrizes da cooperativa. A COOPEMATER encontra dificuldade na transmissão das informações (comunicação deficiente), não se utili- zando de veículos como a televisão, o rádio, o jornal, entre outros, para que a disseminação da informação, no quadro social, se concretize. Porém, em alguns quesitos como divulgação em banners, locais estratégicos dentro e fora da cooperativa, materiais gráficos e site da organização, a comunicação é realizada. Por fim, a sua ausência nas préassembleias não significa a falta de confiança na administração do negócio.

O último bloco de afirmativas (13 a 17) avaliaram a razão pessoal que leva os associados às préassembleias nas seccionais. Os dados são apresentados na Tabela 3.

Tabela 3 - Razões Pessoais

\begin{tabular}{l|l}
\hline Razões pessoais & Média \\
\hline Eleição com existência de chapa concorrente & 3,0 \\
Decisão sobre rateio das perdas & 3,2 \\
Aprovação das contas e destinação do FATES & 3,1 \\
Festividades e brindes distribuídos & 2,6 \\
Rateio das sobras & 3,3 \\
\hline Média Geral & 3,04 \\
\hline
\end{tabular}

Fonte: Dados da Pesquisa (2014)

A Tabela 3 evidencia que o rateio das sobras e das perdas, respectivamente, são as principais razões pelas quais os associados participam de uma pré-assembleia. Isso se justifica pelo fato dos cooperados serem os donos do empreendimento e precisarem entendê-lo. Nesse sentido, é necessário que a cooperativa desenvolva ferramentas que divulguem as pré-assembleias, estimulando a participação e a compreensão dos cooperados.
A importância da representação por meio de delegados em assembleia geral fica evidenciada em parte, ao longo do estudo realizado, ao apontar que, na COOPEMATER/PA, a existência do mecanismo democrático de participação carece de ajustes. Entretanto, com a implementação da representação por delegados, toda a área de abrangência da cooperativa terá participação efetiva nas decisões, dando-lhes maior legitimidade. 


\section{Considerações finais}

Este estudo procurou examinar a percepção dos cooperados na participação das decisões por meio da representação por delegados nas assembleias gerais da cooperativa SICOOB COPEMATER. A premissa básica desta pesquisa foi a de que a participação nas decisões por meio da representação por delegados é um fator determinante para uma maior representatividade dos associados e para a legitimidade dos processos de controle interno.

Dada as propostas da investigação em, primeiramente, verificar a participação dos associados nas decisões da cooperativa, observa-se o baixo interesse dos associados por assuntos relacionados à organização. A participação nas pré-assembleias deve-se principalmente à possibilidade de decidirem sobre o rateio das perdas e das sobras.

O motivo principal para a não participação é a dificuldade de deslocamento até o local da assembleia, seguido pela falta de divulgação desta pela cooperativa. Desenvolver práticas de estímulo à representatividade garantirá o avanço nessa área, bem como o equilíbrio democrático.

A ampliação dos espaços de participação direta dos associados permitirá que comuniquem seus interesses aos representantes e, com isso, sejam sensibilizados para as suas demandas e necessidades.

A pesquisa aponta que a cooperativa estudada não difere substancialmente dos estudos já realizados e informados neste texto, ou seja, as semelhanças se mostraram bem mais evidentes do que as diferenças.

De qualquer sorte, vale a pena sugerir estratégias que poderão ser utilizadas para melhorar a participação nas assembleias e contribuir para a aproximação dos interesses dos representados à ação dos representantes. Em termos de ampliação de participação, sugere-se o uso de videoconferências, permitindo que cada grupo reúna-se sem sair de suas respectivas localidades.

Por fim, a gestão democrática, a participação e a autogestão podem ser consideradas construções coletivas capazes de consolidar a participação dos associados nas decisões por meio da representação por delegados.

\section{Referências}

ALIANÇA COOPERATIVA INTERNACIONAL. Disponível em < http://www.ica.coop>. Acesso em 20 de dezembro de 2013.

BASSO, R.A.; DUARTE, E., e FLORES, A.J. O programa a união faz a vida: uma experiência de educação cooperativa nas comunidades da região da produção. In: Revita Reflexão Cooperativista. Porto Alegre: SESCOOP, 2012.

BIRCHALL, J. e SIMMONS, R. Whats motivates members to participate in cooperative and mutual business? Annals of public e cooperative economics, v. 75, n.3, p. 465-495, sep. 2004.

BORDENAVE,J.E.D. O que é participação? São Paulo: Brasiliense, 1994.

BRANDALISE, L.T. Modelos de medição de percepção e comportamento: uma revisão. Relatório Técnico. Universidade Estadual do Oeste do Paraná (UNIOESTE), 2005. Disponível em <http://www.lgti.ufsc.br/brandalise.pdf >. Acesso em: 15 out. 2014.

BRASIL. Decreto n ${ }^{\circ} 22.239$ de 19 de Dezembro de 1932. Reforma as disposições do Decreto Legislativo $\mathrm{n}^{\mathrm{o}} 1.637$, de 05 de janeiro de 1907 , na parte referente às sociedades cooperativas. Rio de Janeiro: CLBR, 1932.

Lei $n^{\circ} 5.764$ de 16 de Dezembro de 1971. Define a política nacional de cooperativismo, institui o regime jurídico das sociedades cooperativas e dá outras providencias. Brasília: D.O.U., 1971.

Lei $\mathrm{n}^{\circ} 6.981$ de 30 de março de 1982. Altera a redação do artigo 42 da Lei no ${ }^{\circ}$ 5.764/71.

DUARTE, L.B. e VIEIRA,P.G.L. Manual de orientações: assembleia de cooperativas. São Paulo: Livronovo, 2010.

FILHO, J.R.F.; MARUCCI, J.C. e OLIVEIRA, M.J. de. Governança cooperativa: participação e representatividade em cooperativas de crédito no Brasil. In: V Encontro de Investigadores Latino- 
americanos de cooperativismo. Ribeirão Preto, SP, Brasil, Agosto de 2008.

HOLANDA, H.A.L. As percepções dos formadores de opinião sobre os fatores relacionados á indução do desenvolvimento local e a participação do cooperativismo nesse processo: o caso de Santa Maria de Jetibá. Dissertação (mestrado em Administração). Universidade Federal do Espírito Santo, 2003.

KREIMEIER, R. O crescimento da participação de associados jovens no quadro social da cooperativa Languiru. Lajeado: Editora do Autor, 2010.

MANICA, S.A.; SCHMIDT, C.E.F. O confronto ideológico do cooperativismo na economia de mercado. In: Revista Reflexão Cooperativista. Porto Alegre: Sescoop/RS, 2012.

MARQUES, A.C.A. Faces do cooperativismo. Dissertação (mestrado em Administração). Universidade federal do Paraná, Curitiba, 2010.

MATTOS, S.A. de. Participação, comprometimento e satisfação dos associados: uma análise da Cooperativa Mista Vista Gaúcha- COOPERVISTA. In: Revista Reflexão Cooperativista. Porto Alegre: SESCOOP/RS, 2013.

MEINEN, E. e PORT, M. O cooperativismo de crédito ontem, hoje e amanhã. Brasília/DF: CONFEBRAS, 2012.

PINHEIRO, M.A.H. Cooperativas de crédito: história da evolução normativa no Brasil. Brasília/DF: BCB, 2008.

SINGER, P.A. Recente ressurreição da economia solidária no Brasil. In: SANTOS, B. de S. (Org.). Produzir para viver: os caminhos da produção não capitalista. Rio de Janeiro: Civilização Brasileira, 2002.

VENTURA, E.C.F.; FILHO, J.R.F. e SOARES, M.M. (Coord.). Governança corporativa: diretrizes e mecanismos para fortalecimento da governança em cooperativas de crédito. Brasília/DF:

BCB, 2009. 
